\title{
Optimasi Multirespon Proses Wire-EDM Menggunakan Metode Taguchi Logika Fuzzy
}

Pathya $^{1, a)}$,Bobby Oedy Pramoedyo Soepangkat ${ }^{2, b)}$

\author{
${ }^{1)}$ Laboratorium Proses Produksi \\ Program Studi Teknik Mesin, Institut Teknologi Indonesia, \\ Jl. Raya Puspiptek, Serpong-Tangerang, Banten 15320 \\ ${ }^{2)}$ Laboratorium Proses Manufaktur \\ Jurusan Teknik Mesin, Fakultas Teknologi Industri, Institut Teknologi Sepuluh Nopember Surabaya \\ Jl. Raya ITS, Keputih, Sukolilo, Keputih, Surabaya, Jawa Timur 60117 \\ a) pr_pathya@iti.ac.id, b) bobs_1994@me.its.ac.id
}

\begin{abstract}
Abstrak
Penelitian ini membahas optimasi proses pemesinan wire-EDM multirespon karakteristik menggunakan metode Taguchi dan logika fuzzy. Multirespon yang digunakan pada penelitian ini adalah recast layer dan surface roughness dimana masing-masing mempunyai karakteristik kualitas semakin kecil semakin baik. Pada percobaan ini dilakukan dengan memvariasikan enam parameter proses, yaitu on time, open voltage, off time, servo voltage, wire feed, dan water flow. Karena setiap parameter proses tersebut memiliki tiga level, maka rancangan percobaan yang digunakan adalah matriks orthogonal array $\mathrm{L}_{27}$. Untuk mengoptimasi kedua karakteristik dari kedua respon digunakan logika fuzzy. Hasil penelitian menunjukkan bahwa karakteristik dari kedua respon tersebut mengalami peningkatan secara efektif dengan metode ini. Parameter proses pemesinan yang secaara signifikan mempengaruhi recast layer dan surface roughness adalah on time, open voltage dan wire feed.
\end{abstract}

Kata kunci: wire-EDM, Taguchi, logika fuzzy, recast layer, surface roughness

\begin{abstract}
This paper presents the optimization of the wire electrical discharge machining (Wire-EDM) process with multiresponse characteristics based on the orthogonal array with Taguchi-fuzzy method. The experimental studies were conducted under varying wire-EDM process variables i.e. on time, open voltage, off time, servo voltage, wire feed, and water flow. The optimized multiple performance were thickness of recast layer and surface roughness The quality characteristic of thickness of recast layer and surface roughness were smaller-is-better. Since each factors had three levels, the experiment design used $L_{27}$ orthogonal array with three replications. Fuzzy logic is used to optimize the characteristics of both responses. Experimental results have shown machining performance in the wire-EDM process can be can be improved effectively through this method. The WEDM process variables which significantly affected recast layer and surface roughness are on time, open voltage, and wire feed..
\end{abstract}

Keywords: Wire-EDM, Taguchi, Fuzzy Logic, Recast Layer, Surface Roughness 


\section{PENDAHULUAN}

Proses pemesinan wire-EDM (Electro Discharge Machinig) merupakan proses termoelektrik yang menyebabkan benda kerja terkikis karena pelepasan muatan listrik yang mengakibatkan timbulnya rangkaian bunga api listrik diantara benda kerja dan elektroda. Proses Wire-EDM ini digunakan pada material yang koduktif dengan bentuk kompleks yang tidak dapat dikerjakan dengan mesin konvensional biasa dimana membutuhkan kekasaran permukaan yang rendah serta ketelitian dan kepresisian geometri yang tinggi. Selain itu Biasanya, proses wire-EDM menggunakan kawat elektroda yang memiliki diameter 0,05 sampai dengan 0,4 mm. Beberapa aplikasi dari proses ini digunakan pada proses pembuatan cetakan dan pahat potong [1] [2].

Parameter proses wire-EDM seperti on time, off time, servo voltage, dan peak current mempunyai pengaruh terhadap recast layer [3]. Selain recast layer, karakteristik kualitas respon untuk produk akhir hasil dari proses pemesinan wire-EDM adalah kekasaran permukaan benda kerja. Proses pemesinan seperti pulse on time, pulse off time, peak current, flushing pressure, wire feed, wire tension, spark gap, dan servo feed mempunyai pengaruh terhadap kekasaran permukaan benda kerja pada proses wire-EDM [4] [6].

Dalam memperbaiki dan mengendalikan kualitas produk dan proses, dibutuhkan metode pengaturan dalam menentukan kombinasi parameter proses yang tepat. Salah satunya adalah mengggunakan metode Taguchi. Akan tetapi metode Taguchi hanya bisa digunakan untuk mengoptimasi proses pada satu respon [7]. Penyelesaian dalam mengoptimasi secara serentak lebih dari satu repon (multirespon) adalah dengan menggunakan kombinasi metode Taguchi dan logika fuzzy [8] [9]. Dalam penelitian ini, karakteristik multirespon yang akan digunakan pada proses pemesinan wire-EDM dengan metode Taguchi logika fuzzy, yaitu recast layer dan surface roughness.

\section{METODE EKSPERIMEN}

\subsection{Bahan Penelitian}

Material yang digunakan pada penelitian ini adalah baja AISI D2 dengan dimensi $200 \mathrm{~mm}$ x $30 \mathrm{~mm}$ x $15 \mathrm{~mm}$. Kekerasan baja ini adalah 60HRC. Bahan elektroda kawat yang digunakan adalah kuningan dengan diameter $0,25 \mathrm{~mm}$.

\subsection{Peralatan Penelitian}

\section{Mesin Wire-EDM}

Mesin Wire-EDM yang digunakan pada penelitian ini adalha CHMER CW32F, dengan arah pergerakan lima sumbu (x. y, z, u, dan v), diameter kawat 0,15-0,3 mm, kecepatan kawat maksimal $250 \mathrm{~mm} /$ detik dan dimensi benda kerja $600 \mathrm{~mm}$ x $400 \mathrm{~mm}$.

2. Miroskop optik

Pada penelitian ini, untuk mengukur ketebalan dari recast layer digunakan mikroskop optik dengan perbesaran 500x.

\section{Alat ukur kekasaran permukaan}

Untuk mengetahui besarnya kekasaran permukaan produk menggunakan Mitutoyo Surftest 401 dengan ketelitian $0,1 \mu \mathrm{m}$.

\subsection{Rancangan Percobaan}

Ada enam parameter proses yang digunakan dalam percobaaan ini dimana setiap parameter proses pemesinan wire-EDM memliki tiga level pengaturan. Pengaturan level ini ditunjukkan pada Tabel 1.

Tabel 1. Pengaturan level pada setiap parameter proses

\begin{tabular}{ccccc} 
Parameter proses & Unit & Level 1 & Level 2 & Level 3 \\
\hline On Time $($ ON $)$ & $\mu \mathrm{s}$ & 0,4 & 0,6 & 0,8 \\
Open Voltage $(\boldsymbol{O V})$ & Volt & 75 & 80 & 85 \\
Off Tme $($ OFF $)$ & $\mu \mathrm{s}$ & 10 & 11 & 12 \\
Servo Voltage $(\boldsymbol{S V})$ & Volt & 30 & 35 & 40 \\
Wire Feed $(\boldsymbol{W S})$ & $\mathrm{mm} / \mathrm{s}$ & 170 & 200 & 220 \\
Water Flow $(\boldsymbol{W F})$ & $\mathrm{kg} / \mathrm{cm}^{2}$ & 5 & 10 & 15 \\
\hline
\end{tabular}

Metode eksperimen yang digunakan pada penelitian ini adalah metode Taguchi dengan rancangan percobaan orthogonal array $\mathrm{L}_{27}$ yang ditunjukkan pada Tabel 2 . Percobaan ini menggunakan tiga kali replikasi.

Tabel 2. Rancangan percobaan orthogonal array $\mathrm{L}_{27}$

\begin{tabular}{ccccccc}
\hline \multirow{2}{*}{$\begin{array}{c}\text { Percobaan } \\
\text { ke- }\end{array}$} & \multicolumn{5}{c}{ Parameter Proses } \\
\cline { 2 - 6 } & ON & OV & OFF & SV & WS & WF \\
\hline 1 & 1 & 1 & 1 & 1 & 1 & 1 \\
2 & 1 & 1 & 2 & 2 & 2 & 2 \\
3 & 1 & 1 & 3 & 3 & 3 & 3 \\
4 & 1 & 2 & 1 & 2 & 2 & 3 \\
5 & 1 & 2 & 2 & 3 & 3 & 1 \\
6 & 1 & 2 & 3 & 1 & 1 & 2 \\
7 & 1 & 3 & 1 & 3 & 3 & 2 \\
8 & 1 & 3 & 2 & 1 & 1 & 3 \\
9 & 1 & 3 & 3 & 2 & 2 & 1 \\
10 & 2 & 1 & 1 & 2 & 3 & 2 \\
11 & 2 & 1 & 2 & 3 & 1 & 3 \\
12 & 2 & 1 & 3 & 1 & 2 & 1 \\
13 & 2 & 2 & 1 & 3 & 1 & 1 \\
14 & 2 & 2 & 2 & 1 & 2 & 2 \\
15 & 2 & 2 & 3 & 2 & 3 & 3 \\
16 & 2 & 3 & 1 & 1 & 2 & 3 \\
17 & 2 & 3 & 2 & 2 & 3 & 1 \\
18 & 2 & 3 & 3 & 3 & 1 & 2 \\
19 & 3 & 1 & 1 & 3 & 2 & 3 \\
20 & 3 & 1 & 2 & 1 & 3 & 1 \\
21 & 3 & 1 & 3 & 2 & 1 & 2 \\
22 & 3 & 2 & 1 & 1 & 3 & 2 \\
23 & 3 & 2 & 2 & 2 & 1 & 3 \\
24 & 3 & 2 & 3 & 3 & 2 & 1 \\
25 & 3 & 3 & 1 & 2 & 1 & 1 \\
26 & 3 & 3 & 2 & 3 & 2 & 2 \\
27 & 3 & 3 & 3 & 1 & 3 & 3 \\
\hline & & & & & &
\end{tabular}

Berikut ini merupakan langkah-langkah optimasi metode Taguchi dengan logika fuzzy :

\section{Melakukan perhitungan $\mathrm{S} / \mathrm{N}$ Rasio pada setiap respon}

$\mathrm{S} / \mathrm{N}$ rasio digunakan untuk memilih parameter proses yang memiliki kontribusi pada pengurangan 
variasi suatu karakteristik kualiatas respon. $\mathrm{S} / \mathrm{N}$ rasio merupakan rancangan untuk melakukan transformasi pengulangan data ke dalam suatu nilai yang merupakan ukuran variasi yang timbul. Karakteristik kualitas respon optimal yang digunakan pada penelitian ini adalah semakin kecil semakin baik untuk recast layer dan surface roughness. Oleh karena itu, persamaan untuk menghitung $\mathrm{S} / \mathrm{N}$ rasio adalah [11-12]:

$$
\mathrm{S} / \mathrm{N}=-10 \log \left[\sum_{i=1}^{n} \frac{y_{i}^{2}}{n}\right]
$$

Dengan: $\mathrm{n}=$ jumlah replikasi

$$
y_{i}=\text { nilai dari karakteristik kualitas respon }
$$

\section{Melakukan tahap Fuzzification}

Fuzzification merupakan proses pengubahan nilai awal, yaitu S/N rasio menjadi bilangan fuzzy dengan menggunakan fungsi keanggotaan (membership function). Fungsi keanggotaan adalah suatu kurva yang digunakan untuk menunjukkan pemetaan titik-titik input data ke dalam nilai keanggotaannya (sering juga disebut dengan derajat keanggotaan). Bentuk dari fungsi keanggotaan yang digunakan adalah kurva segitiga.

\section{Membuat fuzzy rules}

Setelah tahap fuzzification, kemudian membuat fuzzy rules untuk mendapatkan nilai fuzzy. Fuzzy rules merupakan aturan yang menjelaskan mengenai hubungan antara output dan nilai-nilai tertentu pada masing-masing variabel input juga sebagai alat penarik kesimpulan yang akan menghasilkan nilai fuzzy berdasarkan logika fuzzy. Biasanya fuzzy rules dibuat berdasarkan pengelompokkan dengan bentuk batasan aturan if-then (jika-maka). Fuzzy rules yang digunakan pada penelitian ini adalah sebagai berikut:

1. Jika (recast layer adalah rendah) dan (surface roughness adalah rendah), maka (FRG adalah sangat rendah)

2. Jika (recast layer adalah rendah) dan (surface roughness adalah medium), maka (FRG adalah rendah)

3. Jika (recast layer adalah rendah) dan (surface roughness adalah tinggi), maka (FRG adalah medium)

4. Jika (recast layer adalah medium) dan (surface roughness adalah rendah), maka (FRG adalah rendah)

5. Jika (recast layer adalah medium) dan (surface roughness adalah medium), maka (FRG adalah medium)

6. Jika (recast layer adalah medium) dan (surface roughness adalah tinggi), maka (FRG adalah tinggi)
7. Jika (recast layer adalah tinggi) dan (surface roughness adalah rendah), maka (FRG adalah medium)

8. Jika (recast layer adalah tinggi) dan (surface roughness adalah medium), maka (FRG adalah tinggi)

9. Jika (recast layer adalah tinggi) dan (surface roughness adalah tinggi), maka (FRG adalah sangat tinggi)

Dalam penelitian ini fungsi keanggotaan untuk input respon recast layer dan surface roughness dibagi menjadi tiga fuzzy subsets, yaitu small (S), medium (M) dan large (L).

\section{Melakukan tahap Defuzzification}

Defuzzification merupakan proses pengubahan nilai fuzzy menjadi Fuzzy Reasoning Grade (FRG) dengan cara melakukan pemetaan himpunan fuzzy ke himpunan tegas (crisp). Metode yang paling sering digunakan

pada proses defuzzification adalah metode centroid. Pada metode ini, defuzzification dilakukan dengan cara mentransformasikan output multirespon $\left(\mu_{C O}\right)$ menjadi non-fuzzy value (yo), atau yang disebut FRG. Metode ini dapat dirumuskan sebagai berikut [10]:

$$
y o=\frac{\sum y \boldsymbol{\mu}_{\boldsymbol{c}_{\mathbf{0}}}(y)}{\sum \boldsymbol{\mu}_{\boldsymbol{c}_{\mathbf{0}}}(y)}
$$

Dalam penelitian ini, variabel output dari sistem logika fuzzy adalah FRG yang diubah ke dalam lima fuzzy subsets dengan menggunakan fungsi keanggotaan yang berbentuk segitiga, yaitu very small (VS), small $(\mathrm{S})$, middle $(\mathrm{M})$, large $(\mathrm{L})$, dan very large (VL), seperti yang ditunjukkan pada Gambar 5 .

\section{Melakukan tahap Analisis Variansi (ANAVA)}

Analisis variansi (ANAVA) digunakan untuk mengetahui variabel proses yang memiliki pengaruh secara signifikan terhadap respon dan besarnya kontribusi variabel proses terhadap respon. Pada penelitian ini, analisis variansi dilakukan pada FRG yang merupakan respon yang mewakili keseluruhan respon.

Secara statistik, nilai $F$-test menunjukkan keputusan parameter proses mana yang mempunyai pengaruh besar terhadap respon. Semakin besar nilai F-value mengindikasikan bahwa variasi parameter proses tersebut akan sangat berpengaruh terhadap nilai respon. Parameter proses dikatakan berpengaruh secara signifikan terhadap respon ketika mempunyai nilai $F$ value yang lebih besar dibanding $\mathrm{F}_{\alpha \text {, v1, v2 (nilai dapat }}$ dilihat pada tabel statistik). 
Persen kontribusi menunjukkan porsi (kekuatan relatif) masing-masing faktor terhadap total variansi yang diamati. Jika persen kontribusi error kurang dari lima belas persen, maka tidak ada faktor yang berpengaruh terabaikan tetapi jika persen kontribusi error lebih dari lima belas persen mengindikasikan ada faktor yang berpengaruh terabaikan sehingga error yang terjadi terlalu besar. Jumlah derajat kebebasan error sangat disarankan tidak melebihi dari setengah derajat kebebasan total [10-11]. Pada kasus ini, jumlah derajat kebebasan error masih kurang dari lima puluh persen untuk setengah derajat kebebasan dalam matriks ortogonal.

\section{HASIL DAN PEMBAHASAN}

Hasil percobaan adalah berupa nilai dari recast layer dan kekasaran permukaan berdasarkan rancangan percobaan metode Taguchi orthogonal array $\mathrm{L}_{27}$ yang ditunjukkan pada Tabel 3.

Tabel 3. Hasil percobaan untuk respon recast layer dan surface roughnes

\begin{tabular}{|c|c|c|c|c|c|c|c|c|c|c|}
\hline \multirow{3}{*}{$\begin{array}{c}\text { Percobaan } \\
\text { ke- }\end{array}$} & \multirow{2}{*}{\multicolumn{6}{|c|}{ Parameter Proses }} & \multicolumn{4}{|c|}{ Respon } \\
\hline & & & & & & & \multicolumn{2}{|c|}{ Recast Layer } & \multicolumn{2}{|c|}{$\begin{array}{c}\text { Surface } \\
\text { Roughness }\end{array}$} \\
\hline & ON & ov & OFF & SV & WS & WF & Mean & $\begin{array}{c}\mathrm{S} / \mathrm{N} \\
\text { Ratio } \\
\end{array}$ & Mean & $\begin{array}{r}\mathrm{S} / \mathrm{N} \\
\text { Ratio } \\
\end{array}$ \\
\hline 1 & 1 & 1 & 1 & 1 & 1 & 1 & 1,58 & $-4,06$ & 1,61 & $-4,12$ \\
\hline 2 & 1 & 1 & 2 & 2 & 2 & 2 & 1,21 & $-11,1$ & 1,79 & $-5,09$ \\
\hline 3 & 1 & 1 & 3 & 3 & 3 & 3 & 2,88 & $-9,2$ & 2,06 & $-6,27$ \\
\hline 4 & 1 & 2 & 1 & 2 & 2 & 3 & 2,81 & $-9,03$ & 2,15 & $-6,68$ \\
\hline 5 & 1 & 2 & 2 & 3 & 3 & 1 & 3,49 & $-10,9$ & 2,15 & $-6,65$ \\
\hline 6 & 1 & 2 & 3 & 1 & 1 & 2 & 4,3 & $-12,7$ & 2,24 & $-7,00$ \\
\hline 7 & 1 & 3 & 1 & 3 & 3 & 2 & 3,7 & $-11,4$ & 1,98 & $-5,95$ \\
\hline 8 & 1 & 3 & 2 & 1 & 1 & 3 & 2,75 & $-8,86$ & 1,96 & $-5,85$ \\
\hline 9 & 1 & 3 & 3 & 2 & 2 & 1 & 4,07 & $-12,2$ & 2,24 & $-7,03$ \\
\hline 10 & 2 & 1 & 1 & 2 & 3 & 2 & 5,2 & $-14,4$ & 2,39 & $-7,62$ \\
\hline 11 & 2 & 1 & 2 & 3 & 1 & 3 & 2,93 & $-9,5$ & 2,11 & $-6,58$ \\
\hline 12 & 2 & 1 & 3 & 1 & 2 & 1 & 3,21 & $-10,1$ & 2,23 & $-6,98$ \\
\hline 13 & 2 & 2 & 1 & 3 & 1 & 1 & 13,3 & $-22,5$ & 1,74 & $-4,79$ \\
\hline 14 & 2 & 2 & 2 & 1 & 2 & 2 & 13,35 & $-22,5$ & 2,25 & $-7,05$ \\
\hline 15 & 2 & 2 & 3 & 2 & 3 & 3 & 9,1 & $-19,2$ & 2,39 & $-7,57$ \\
\hline 16 & 2 & 3 & 1 & 1 & 2 & 3 & 4,75 & $-13,6$ & 2,48 & $-7,89$ \\
\hline 17 & 2 & 3 & 2 & 2 & 3 & 1 & 7,59 & $-17,7$ & 2,14 & $-6,59$ \\
\hline 18 & 2 & 3 & 3 & 3 & 1 & 2 & 9,83 & $-19,9$ & 2,38 & $-7,54$ \\
\hline 19 & 3 & 1 & 1 & 3 & 2 & 3 & 2,69 & $-8,61$ & 2,41 & $-7,63$ \\
\hline 20 & 3 & 1 & 2 & 1 & 3 & 1 & 0,37 & 6,92 & 2,8 & $-8,93$ \\
\hline 21 & 3 & 1 & 3 & 2 & 1 & 2 & 1,5 & $-4,13$ & 2,66 & $-8,51$ \\
\hline 22 & 3 & 2 & 1 & 1 & 3 & 2 & 7,09 & $-17,1$ & 2,63 & $-8,41$ \\
\hline 23 & 3 & 2 & 2 & 2 & 1 & 3 & 7,34 & $-17,3$ & 2,44 & $-7,74$ \\
\hline 24 & 3 & 2 & 3 & 3 & 2 & 1 & 10,59 & $-20,5$ & 2,81 & $-8,99$ \\
\hline 25 & 3 & 3 & 1 & 2 & 1 & 1 & 7,67 & $-17,7$ & 2,77 & $-8,85$ \\
\hline 26 & 3 & 3 & 2 & 3 & 2 & 2 & 8,72 & $-18,8$ & 2,55 & $-8,13$ \\
\hline 27 & 3 & 3 & 3 & 1 & 3 & 3 & 6,81 & $-16,7$ & 3 & $-9,55$ \\
\hline
\end{tabular}

Setelah hasil $\mathrm{S} / \mathrm{N}$ rasio diperoleh, selanjutnya dilakukan fuzzification. Variable respon (input) pada penelitian ini adalah recast layer dan surface roughnes $s$. Bentuk dari fungsi keanggotaan yang digunakan adalah kurva segitiga. Pada umumnya, fungsi keangotaan dibagi menjadi tiga subsets, yaitu small (S), medium (M), dan large (L), seperti yang ditunjukkan pada Gambar 1 dan 2.

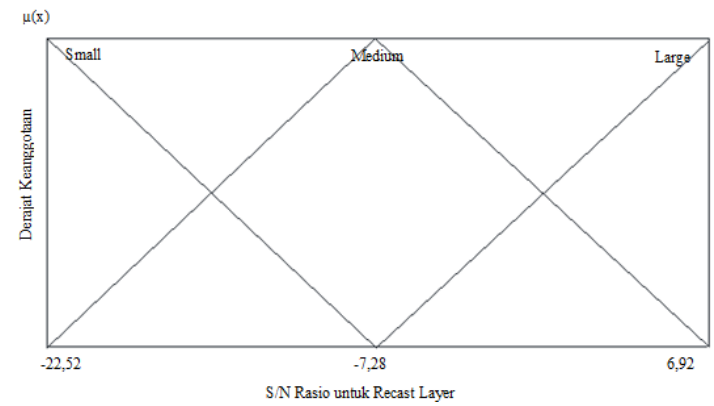

Gambar 1. Fungsi keanggotaan untuk Recast Layer

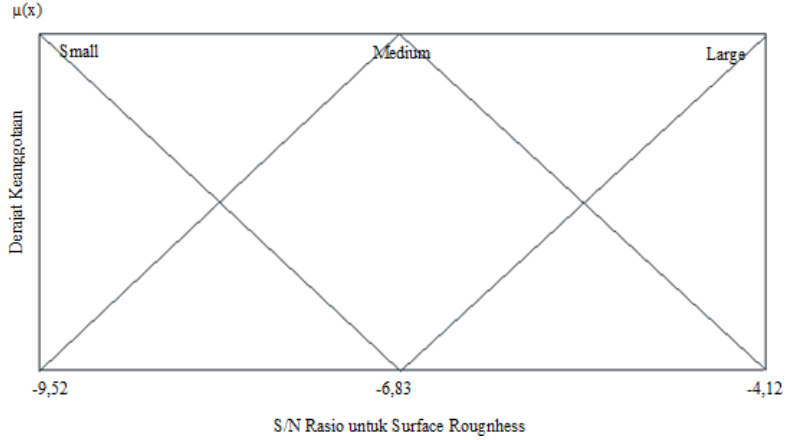

Gambar 2. Fungsi keanggotaan untuk Surface Roughness

Fuzzy Reasoning Grade (FRG) merupakan variabel output pada logika fuzzy. FRG diubah kedalam lingistic fuzzy subsets menggunakan fungsi keanggotaan yang berbentuk segitiga. Fungsi keanggotaan untuk variabel output dibagi menjadi lima fuzzy subsets yaitu very small $(V S)$, small $(S)$, medium $(M)$, large $(L)$ dan very large (VL). Grafik fungsi keanggotaan untuk FRG ditunjukkan pada Gambar 3.

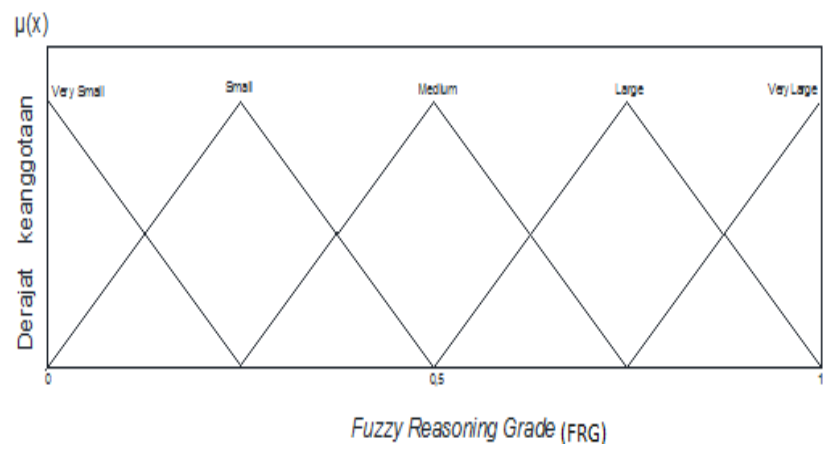

Gambar 3. Fungsi keanggotaan untuk FRG

Fuzzy rules yang dibuat menggunakan S/N Rasio yang berasal dari variabel respon (recast layer dan surface roughness) sebagai variabel input dan FRG sebagai variabel output. 
Defuzzification dengan metode centroid merupakan proses yang digunakan untuk mengubah nilai fuzzy menjadi FRG. Perubahan nilai tersebut dilakukan dengan cara memetakan himpunan fuzzy ke himpunan tegas (crisp).

Nilai FRG yang berasal dari proses defuzzification merupakan variabel respon yang mewakili recast layer dan surface roughness. Tabel 4 menujukkan nilai dari FRG ini, sedangkan perhitungan rata-rata nilai FRG pada setiap level dari parameter proses ditunjukkan pada Tabel 5.

Tabel 4. Hasil nilai FRG

\begin{tabular}{|c|c|c|}
\hline $\begin{array}{c}\text { Percobaan } \\
\text { ke- }\end{array}$ & $\begin{array}{l}\text { Nilai } \\
\text { FRG }\end{array}$ & $\begin{array}{c}\text { S/N Rasio } \\
\text { FRG }\end{array}$ \\
\hline 1 & 0,759 & $-2,401$ \\
\hline 2 & 0,578 & $-4,761$ \\
\hline 3 & 0,530 & $-5,511$ \\
\hline 4 & 0,492 & $-6,159$ \\
\hline 5 & 0,460 & $-6,739$ \\
\hline 6 & 0,408 & $-7,780$ \\
\hline 7 & 0,516 & $-5,740$ \\
\hline 8 & 0,571 & $-4,863$ \\
\hline 9 & 0,415 & $-7,637$ \\
\hline 10 & 0,373 & $-8,575$ \\
\hline 11 & 0,494 & $-6,131$ \\
\hline 12 & 0,450 & $-6,943$ \\
\hline 13 & 0,429 & $-7,345$ \\
\hline 14 & 0,249 & $-12,083$ \\
\hline 15 & 0,307 & $-10,246$ \\
\hline 16 & 0,373 & $-8,566$ \\
\hline 17 & 0,375 & $-8,515$ \\
\hline 18 & 0,297 & $-10,536$ \\
\hline 19 & 0,417 & $-7,595$ \\
\hline 20 & 0,567 & $-4,928$ \\
\hline 21 & 0,434 & $-7,250$ \\
\hline 22 & 0,320 & $-9,897$ \\
\hline 23 & 0,330 & $-9,640$ \\
\hline 24 & 0,235 & $-12,593$ \\
\hline 25 & 0,289 & $-10,770$ \\
\hline 26 & 0,302 & $-10,394$ \\
\hline 27 & 0,203 & $-13,859$ \\
\hline
\end{tabular}

Sumber: Perhitungan

Tabel 5. Perhitungan rata-rata nilai FRG pada setiap level parameter proses

\begin{tabular}{cccc}
\multicolumn{3}{c}{ parameter proses } \\
$\begin{array}{c}\text { Parameter } \\
\text { Proses }\end{array}$ & Level 1 & Level 2 & Level 3 \\
\hline ON & 0,5256 & 0,3719 & 0,3441 \\
OV & 0,5112 & 0,3589 & 0,3714 \\
OFF & 0,4218 & 0,3857 & 0,434 \\
SV & 0,4052 & 0,4249 & 0,4114 \\
WS & 0,4409 & 0,4362 & 0,3644 \\
WF & 0,4467 & 0,4062 & 0,3886 \\
\hline Rata-rata & 0,4138 & \\
\hline \hline
\end{tabular}

Plot untuk nilai rata-rata dari FRG pada setiap level dari parameter proses, yaitu on time, open voltage, off time, servo voltage, wire feed dan water flow yang ditunjukkan pada Gambar 4

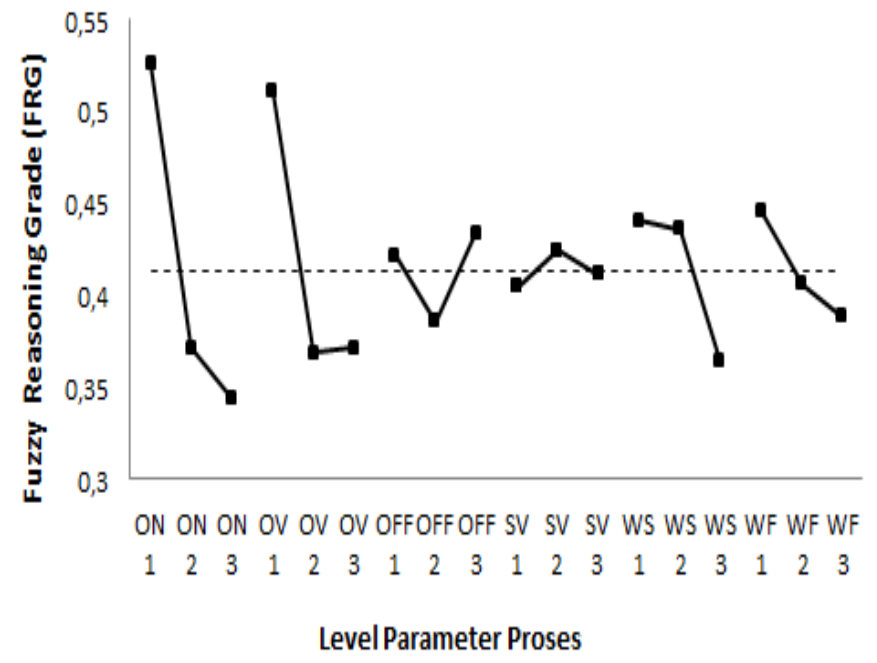

Gambar 4. Plotting nilai FRG pada setiap level parameter proses

Tabel 6 menunjukkan hasil Analisis Variansi (ANAVA) dari FRG. Hasil ANAVA dilakukan untuk mengetahui parameter proses yang mempunyai pengaruh secara signifikan terhadap variabel respon.

Tabel 6. Analisis Variansi dan Persen Kontribusi

\begin{tabular}{cccccccc}
\hline Source & DF & SS & MS & SS $^{\prime}$ & $\mathbf{F}$ & $\begin{array}{c}\boldsymbol{\rho}- \\
\text { value }\end{array}$ & $\begin{array}{c}\% \\
\text { kontribusi }\end{array}$ \\
\hline ON & 2 & 0,172 & 0,086 & 0,172 & 24,45 & 0,000 & 41,73 \\
OV & 2 & 0,129 & 0,064 & 0,129 & 18,28 & 0,000 & 31,20 \\
OFF & 2 & 0,011 & 0,006 & 0,011 & 1,62 & 0,233 & 2,76 \\
SV & 2 & 0,002 & 0,001 & 0,002 & 0,26 & 0,774 & 0,44 \\
WS & 2 & 0,033 & 0,017 & 0,033 & 4,71 & 0,027 & 8,04 \\
WF & 2 & 0,016 & 0,008 & 0,016 & 2,27 & 0,140 & 3,87 \\
\hline Residual & 14 & 0,049 & 0,049 & 0,049 & & & 11,95 \\
Error & & & & & & & 100,00 \\
\hline Total & 26 & 0,412 & &
\end{tabular}

Sumber: Perhitungan

Setelah pengaturan level pada parameter proses untuk kondisi optimal diperoleh, selanjutnya melakukan melakukan percobaan dan verifikasi sesuai dengan level dan pengaturan yang telah diperoleh dari kombinasi level optimal dari parameter proses tersebut, yaitu on time pada level 1, open voltage pada level 1, off time pada level 3, servo voltage pada level 2, wire feed pada level 1 dan water flow pada level 1. Berdasarkan percobaan menggunakan pengaturan pada kondisi optimal, kemudian dilakukan perhitungan $\mathrm{S} / \mathrm{N}$ rasio pada kombinasi awal dan kombinasi optimal seperti yang ditunjukkan pada Tabel 7 
Tabel 7. Perbandingan hasil kombinasi awal dan kombinasi optimum parameer proses

\begin{tabular}{|c|c|c|c|c|}
\hline & \multirow{2}{*}{ Kombinasi Awal } & \multicolumn{2}{|c|}{ Kombinasi Optimal } & \multirow{3}{*}{ Ket } \\
\hline & & Precksi & Eksperimen & \\
\hline $\begin{array}{l}\text { Parameter } \\
\text { Proses } \\
\end{array}$ & $\mathrm{ON}_{2} \mathrm{OV}_{2} \mathrm{OFF}_{2} \mathrm{SV}_{2} \mathrm{WS}_{2} \mathrm{WF}_{2}$ & $\mathrm{ON}_{1} \mathrm{OV}_{1} \mathrm{OFF}_{3} \mathrm{SV}_{2} \mathrm{WS}_{1} \mathrm{WF}_{1}$ & $\mathrm{ON}_{1} \mathrm{OV}_{1} \mathrm{OFF}_{3} \mathrm{SV}_{2} \mathrm{WS}_{1} \mathrm{WF}_{1}$ & \\
\hline $\begin{array}{l}\text { Recast } \\
\text { layer }(\mu \mathrm{m})\end{array}$ & 7,24 & & 4,97 & $\begin{array}{c}\text { Penurunan } \\
31.35 \%\end{array}$ \\
\hline $\begin{array}{l}\text { Surface } \\
\text { Roughness } \\
\text { (um) }\end{array}$ & 2,78 & & 2,00 & $\begin{array}{c}\text { Penurunan } \\
28.05 \%\end{array}$ \\
\hline FRG & 0,2887 & 0,7141 & 0,4880 & $\begin{array}{c}\text { Peningkatan } \\
69.03 \%\end{array}$ \\
\hline
\end{tabular}

\section{KESIMPULAN}

Berdasarkan hasil percobaan dan konfirmasi eksperimen, maka dapat ditarik kesimpulan sebagai berikut:

1. Penggunaan metode Taguchi logika fuzzy mampu meningkatkan performansi dari proses pemesinan Wire-EDM, yaitu recast layer dan surface roughness. Hal ini ditunjukkan dengan nilai recast layer dan surface roughness mengalami penurunan pada kondisi optimum.

2. Parameter proses wire-EDM, seperti on time, open voltage dan wire feed adalah yang paling signifikan dalam mengoptimumkan recast layer dan surface roughness.

3. Berdasarkan konfirmasi eksperimen, besarnya nilai FRG mengalami peningkatan pada kondisi optimum yaitu sebessar $69,03 \%$.

4. Semakin rendah nilai recast layer dan surface roughness menyebabkan semakin baik performansi kinerja pada proses pemesinan WireEDM.

\section{UCAPAN TERIMA KASIH}

Penulis mengucapkan terima kasih kepada Laboratorium Proses Manufaktur Jurusan Teknik Mesin FTI-ITS yang telah menyediakan material dan fasilitas untuk menunjang penelitian ini

\section{REFERENSI}

[1] Pandey, P. C. dan Shan, H. S. (1980), Modern Machining Processes, Tata Mc Graw Hill Publishing Company Limited, New Delhi

[2] Sommer, C. dan Sommer, S. (2005), Complete EDM Handbook, Advanced Publishing Inc., Houston.

[3] Ayu, M. (2006), "Performance Evaluation of Wire Electro-Discharge Machining on Tungsten Carbide," Master Thesis yang tidak dipublikasikan, Universiti Teknologi Malaysia, Johor.

[4] Satyanarayana, B., Rao, P. S., dan Praveen, M. K., "Effect of WEDM Conditions on Surface Roughness: A Parametric Optimisation Using Taguchi Method," International Journal of Advanced Engineering Science and Technologies, Vol. 6, 2008, No. 1, hal. 041-048.

[5] N. Tosun, C, Cogun and A. Inan, "The Effect of Cutting Parameters on Workpiece Surface Roughness in Wire EDM," Machining Science and Technology, vol. 7, 2003, pp. 209-219.
[6] Yadav, M. K., Pandey, M. S., Chaudary, S., dan Murtaza, Q, "Effects of Machining Variables on Surface Roughness in Wire-EDM of AISI D3," International Journals of Engineering Science, Vol. 01, 2012, hal. 66-78.

[7] Kumar, A. dan Singh, D. K., "Strategic Optimization and Investigation Effect of Process Parameters on Performance of Wire Electric Discharge Machine," International Journal of Engineering Science and Technology (IJEST), Vol. 4,2012, hal. 2766-2772.

[8] Soejanto, I. Desain Eksperimen dengan Metode Taguchi. Graha Ilmu, Yogyakarta (2009).

[9] Zadeh, L. (1965), "Fuzzy Sets," Jurnal Information and Control, Vol. 8, hal. 338-353.

[10] Lin, C.L., Lin, J.L., and Ko, T.C., Optimisation of the EDM Process Based on the Orthogonal Array with Fuzzy Logic and Grey Relational Analysis Method. The International Jurnal of Advanced Manufacturing Technology. Vol. 19, 2001, pp. 271-277.

[11] D. C. Montgomery. Design and Analysis of Experiment. $7^{\text {th }}$ ed. New York, John Wiley and Sons, Inc., 2009

[12] Park, S.H. Robust Design and Analysis for Quality Engineering 